\title{
Demographic responses of Heterocypris incongruens (Ostracoda) related to stress factors of competition, predation and food
}

\author{
Rocío FERNANDEZ, ${ }^{1}$ Sarma NANDINI, ${ }^{2 *}$ S.S.S. SARMA, ${ }^{2}$ Maria Elena CASTELLANOS-PÁEZ ${ }^{3}$ \\ ${ }^{1}$ Programa de Doctorado en Ciencias Biológicas y de la Salud, Universidad Autónoma Metropolitana, Campus Xochimilco; \\ ${ }^{2}$ Laboratorio de Zoología Acuática, División de Investigación y Posgrado, Universidad Nacional Autónoma de México, Campus Iztacala, \\ Av. de los Barrios \#1, Los Reyes Iztacala, Tlalnepantla, CP 54090; ${ }^{3}$ Laboratory of Rotiferology and Molecular Biology of Plankton, \\ Universidad Autónoma Metropolitana, Campus Xochimilco, Calzada de Hueso No. 1100, Villa de Quietud, Mexico City Z.C. 04960, \\ México \\ *Corresponding author: nandini@unam.mx
}

\begin{abstract}
Heterocypris incongruens is a widely distributed ostracod which can maintain its populations under stressful conditions such as those in temporary ponds and under low-quality diets, for example, detritus. It often co-occurs with cladocerans and fish living in shallow water bodies. Nevertheless, little is known about its response to the presence of predators, its consumption capacity of cyanobacteria typically present in eutrophic systems, and its interaction with other species in similar habits. We studied here the demographic responses of $\mathrm{H}$. incongruens fed the green alga Scenedesmus acutus, two strains of Microcystis $c f$. aeruginosa and Limnothrix sp. Experiments were conducted separately and together in the presence of the cladoceran Simocephalus vetulus and the cichlid fish, Oreochromis kairomones. The ostracod maintained growth in all treatments, the reproductive output decreased on dietary Limnothrix sp., and its life expectancy was significantly lower with the toxic strain of Microcystis. The coexistence of both crustacean species increased the rate of population growth ( 0.33 day $\left.{ }^{-1}\right)$ of $\mathrm{S}$. vetulus and life expectancy (36-44 days) of $\mathrm{H}$. incongruens on the test diets compared with controls (23-33 days). Our study suggests facilitation affects the interaction between the two microcrustaceans, especially on poor quality cyanobacterial diets.
\end{abstract}

Key words: Cladocera; fish kairomones; cyanobacteria; facilitation; demography.

Received: April 2015. Accepted: October 2015.

\section{INTRODUCTION}

Aquatic organisms are subject to anthropogenic and natural stresses (Rapport et al., 1983). Species able to survive under these conditions have developed different life history strategies: they are often " $r$ " strategists with high growth rates (Lahr, 1997), have a high tolerance towards large fluctuations in abiotic factors such as desiccation (Alekseev et al., 2007) and early maturity (Roff, 2001), to name a few. Several species of ostracods have the above mentioned characteristics (Vandekerkhove et a.l, 2013).

Ostracods date back to the Ordovician period (Williams et al., 2008); these organisms have valves that protect them and also preserve well for long periods of time, hence their wide use in paleolimnology (Carbonel et al., 1988). They live in benthic and littoral habitats (Delorme, 1991), are detritivores, grazers and, a few are filter feeders. Their density is mainly related to available resources (Diner et al., 1986), and since ostracods can survive long periods of drought (upto, five weeks; Horne, 1993) they may be early colonizers and therefore can affect the availability of resources for future communities (Diner et al., 1986; Dodson et al., 2005). They are highly tolerant because they inhabit different types of environments, from hot springs to lakes in the Arctic (Delorme, 1991; Külköylüoğlu et al., 2007). Some studies on ostracods have examined different features that allow them to remain in aquatic systems, for example, Rossi et al. (2013) and Vandekerkhove et al. (2013) show that Heterocypris incongruens and Eucypris virens exhibit a high viability in egg resistance to different stresses such as hypoxia, insecticides, digestive enzymes, high salinity, and UV radiation. Horne (1993) and Aguilar-Alberola and Mesquita-Joanes (2011) also show that juvenile and adult Candona patzcuaro and Heterocypris bosniaca can live in dry soil for up to 5 weeks.

In addition, there are other inter-specific relationships that help species persist in a given environment, such as symbiosis, mutualism and facilitation (Begon et al., 2006; Gross et al., 2010). However, with the increased degradation of habitats, changes in inter-specific interactions can occur; facilitation is one of the relationships that occurs in the short term and is therefore not often considered in ecological theories, but there are authors who suggest that it is a fundamental process in physically stressed 
ecosystems (Bruno et al., 2003; Bruno and Kennedy, 2007). Facilitation occurs when an organism builds a favorable habitat for other organisms directly or indirectly, by reducing the stress or increasing the flow of resources (Bruno et al, 2003; Rodriguez, 2006; Gross et al., 2010). Different species of the same or different taxa occur in space and time; Brachionus calyciflorus and B. havanaensis are frequently reported together in eutrophic tropical systems (Alva-Martínez et al., 2009). With regard to this study, Heterocypris incongruens (Ostracoda) and Simocephalus vetulus (Cladocera) often co-occur in temporary bodies of water, shallow ponds and fountains (JuárezFranco et al., 2009; Fernández et al., 2012). In degraded environments, positive interactions such as facilitation, could be an additional cause for organisms to remain in such conditions. The relationship between cyanobacteria and planktonic and benthic microcrustaceans has been studied extensively, mainly focusing on Cladocera and Copepoda (Tillmanns et al., 2008) and to a lesser extent on rotifers (Alva-Martínez et al., 2007) and ostracods (Fernández et al., 2012). While cyanobacterial blooms may explain the low species diversity of zooplankton and phytoplankton (Harper, 1992), there have been recent revisions questioning the effects of these blooms on various organisms (Wilson et al., 2006; Tillmanns et al. 2008). Some species of ostracods consume cyanobacteria efficiently; for example, Eucypris virens (Wickstrom and Castenholz, 1985), Cyprinotus carolinensis (Grant et al., 1983), and H. incongruens (Fernández et al., 2012). Quantifying the changes in demographic variables allows us to understand how organisms adapt to consuming cyanobacterial diets. Eutrophic water bodies are characterized by dense cyanobacterial blooms and dense fish population stocks (Gliwicz, 1990; Harper, 1992).

In this paper the demographic responses of H. incongruens under the following conditions were examined: i) in the presence or absence of $S$. vetulus; ii) in the presence or absence of fish kairomones; and iii) with four diets, Scenedesmus, Limnothrix sp. and two strains of Microcystis sp. A and B (toxic and non-toxic); controls for each treatment were established. Assuming that the ostracod is highly tolerant to stressors, we expected that the demographic variables such as survival and fecundity of Heterocypris incongruens would be similar to the controls in spite of stressors such as low quality diet, coexistence with another organism, and stress from predator stimulii.

\section{METHODS}

\section{Plankton culture}

The test crustacean species were collected from Lake Xochimilco (Mexico City, Mexico). They were maintained under laboratory conditions with moderately hard water $\left(0.9 \mathrm{~g}\right.$ of $\mathrm{NaHCO}_{3}, 0.6 \mathrm{~g}$ of $\mathrm{CaSO}_{4}, 0.6 \mathrm{~g}$ of $\mathrm{MgSO}_{4}$ and $0.04 \mathrm{~g}$ of $\mathrm{KCl}$ dissolved in $1 \mathrm{~L}$ of distilled water; Clesceri et al., 1998), at $25 \pm 1^{\circ} \mathrm{C}$, and were fed Scenedesmus acutus $\left(1.0 \times 10^{6}\right.$ cells $\left.\mathrm{mL}^{-1}\right)$ in one liter beakers and cultures changed twice a week. Before the commencement of the demography experiments, we progressively changed their diet from $S$. acutus to mixed diets containing cyanobacteria Microcystis sp. and Limnothrix sp. This dietary change was performed for 10 days prior to initiating the experiments in order to acclimatize the crustaceans.

We obtained the dominant cyanobacteria using different pore-sized meshes $(500,100,50$ and $20 \mu \mathrm{m})$ to separate the colonies and filaments. We established non-axenic cultures and exposed them to diffused fluorescent light continuously for 15 days. Agglomerated cultures were sonicated for two minutes with an ultra-sonicator (Branson Sonic Power with $20 \mathrm{kHz}$ intensity) (Pérez-Morales et al., 2014). Since the diet had different sizes we offered dry weight equivalents at a final density of $23.2 \mu \mathrm{g} \mathrm{mL}^{-1}$ per day (Mayeli et al., 2004). We tested the cyanobacterial toxicity following Lampert (1987). The strain Microcystis sp. from Chapultepec Lake was toxic (Fernández et al., 2014). Therefore, to differentiate the two strains of Microcystis we used the adjectives toxic to that obtained from Chapultepec Lake and non-toxic to the one obtained from Xochimilco Lake. We follow this for the rest of the document. In order to obtain fish kairomones, we used three Oreochromis sp. fish (size $\sim 4 \mathrm{~cm}$ ), one of the most common fish species in the freshwater bodies of Mexico. They were fed daily, each with 100 individuals of $H$. incongruens and S. vetulus (studies indicate that the alarm signals are produced when predators are fed with conspecific prey; Stabell et al., 2003). The fish were kept in a three liter aquarium with two $L$ of moderately hard water. We filtered the water with a $0.2 \mu \mathrm{m}$ mesh size and transferred the fish to a fresh medium daily.

\section{Life table}

We followed a full factorial design: i) four diets: $S$. acutus (control), Microcystis sp. (toxic), Microcystis sp. (non-toxic), Limnothrix sp.; and for each diet ii) without kairomones and cladocerans (control), with kairomones, without kairomones $+S$. vetulus, with kairomones $+S$. vetulus; a total of 16 treatments, each with four replicates. The experiments were conducted in $100 \mathrm{~mL}$ transparent containers with $50 \mathrm{~mL}$ of the appropriate medium with respect to the algal diet and the presence of cladocerans and /or fish kairomones. Into each recipient we introduced 10 neonates $<24$-hours-old, of only the ostracod. In the treatment to test the impact of cladocerans on H. incongruens we introduced 5 individuals of ostracods and cladocerans, in order to maintain the same initial density. The medium was changed daily; the neonates and dead individuals when encountered, were counted and removed while the 
original members of the cohort were transferred to a fresh medium. The experiment ended when all individuals of the original cohort died. Standard demographic variables were calculated following Krebs (2009):

Gross reproductive rate $=\sum_{0}^{\infty} m_{x}$

Net reproductive rate $R_{o}=\sum_{0}^{\infty} l_{x} \cdot m_{x}$

Average life span: $e_{x}=\frac{T_{x}}{n_{x}}$

Rate of population increase, Euler equation (solved itera-

tively) $\sum_{x=w}^{n} e^{-r x} \cdot l_{x} \cdot m_{x}=1$

(eq. 4),

where

$l_{x}$ is the probability of an individual surviving to an age class;

$m_{x}$ is the age specific fecundity;

$T_{x}$ is days survived after age $\mathrm{x}$;

$\boldsymbol{n}_{x}$ is the number of individuals surviving at the beginning of age class $x$;

$e_{x}$ is life expectancy at age $\mathrm{x}$;

$\mathrm{R}_{\mathrm{o}}$ is the average number of offspring per female;

$r$ is the growth rate of the population.

We compared the demographic variables on each diet and each treatment (presence of cladocerans and or fish kairomones) for statistical significance using $F$-test and Holm-Sidak test (Sigma Plot, ver. 11.0, Systat Software, Inc., Richmond, CA, USA).

\section{RESULTS}

Heterocypris incongruens had a long life span ranging from 40 to 60 days. The survivorship curves showed that the initial mortality of $H$. incongruens was lower on an exclusive diet of Scenedesmus or of either cyanobacteria as compared to phytoplankton with cladocerans, fish kairomones or both (Fig. 1). Regardless of the diet, chlorophyte or cyanobacteria, the ostracods showed improved survivorship in the presence of cladocerans, fish kairomones or both. The presence of fish kairomones, on average, resulted in an increase in survivorship; only $20 \%$ of the ostracods died before first reproduction (within 15 days). On a diet of Microcystis sp. A, the ostracods died earlier in the controls than in the presence of the cladocerans or kairomones. The survival patterns on a diet of Microcystis sp. A but in the presence of cladocerans resulted in an earlier demise of the population (Fig. 1). The reproductive cycle of Heterocypris incongruens can be divided into three phases, pre-reproductive (prior to ma- turity), reproductive (most of the population is reproducing) and post-reproductive (most of the population ceases to reproduce) with the duration of each phase depending on the treatment (Fig. 2). Reproduction began generally ten days after hatching and about $60-100 \%$ of the population reached this phase. The post reproductive phase was longest on diets containing Scenedesmus and shortest on toxic Microcystis. The pre- and post-reproductive phases varied in H. incongruens with relation to the diet (Fig. 2). The impact of the treatments on the pre-reproductive phase was less than that on the post-reproductive phase. The presence of fish kairomones, regardless of the diet, generally improved the reproductive output especially on a diet of Limnothrix. The presence of cladocerans also resulted in an improved fecundity, particularly on diets of the toxic and non-toxic strains of Microcystis.

Life expectancy and reproductive variables are shown in Fig. 3. The mean life span of ostracods ranged from 23 to 43 days, the longest life span was observed in the treatments with the presence of cladocerans $(\mathrm{P}<0.001)$, especially with consumption of Microcystis sp. A (toxic). The life span of $H$. incongruens with cladocerans was $24 \pm 2$ days, and without cladocerans the life expectancy increased by $25 \%$ on the same diet (Fig. 3). The gross reproductive rate was often not significantly different from the controls except on diets of $S$. acutus and Limnothrix where it was significantly lower in the presence of cladocerans $(\mathrm{P}<0.01, \mathrm{~F}$-test). The net reproductive rate, on the other hand, was significantly higher as compared to the controls especially in the presence of cladocerans, fish kairomones or both $(\mathrm{P}<0.01, \mathrm{~F}$-test). The presence of fish kairomones and/or cladocerans resulted in an increase in the net reproductive rate of $H$. incongruens on a diet of both strains of Microcystis. The population growth rate ranged from 0.10 to $0.15 \mathrm{~d}^{-1}$. It was significantly higher on treatments exposed to cladocerans, fish kairomones or both, especially on diets of toxic or non-toxic Microcystis and Limnothrix. The age at first reproduction was also significantly earlier ( $\mathrm{P}<0.01$, F-test $)$, particularly in the presence of fish kairomones (Fig. 4).

\section{DISCUSSION}

Eutrophic water bodies are often beset with multiple stressors (Harper, 1992), particularly for zooplankton due to two main reasons: i) they commonly exhibit cyanobacterial blooms which are considered unsuitable food for zooplankton (Gulati, 1990); ii) dense populations of zooplanktivorous fish feed voraciously on zooplankton, especially those of larger size such as Daphnia (Gliwicz, 2003). Many eutrophic systems are temporary and/or shallow, and exhibit large fluctuations in physical and chemical factors (Moss et al., 1996). Even under these conditions, several taxa are abundant (Lampert, 1986; Tillmanns et al., 2008), especially various species of os- 
tracods (i.e. Mezquita et al., 1999; Külköylüoğlu et al., 2007; Vandekerkhove et al., 2013).

Consumption of cyanobacteria by ostracods has not been widely studied, although a few studies report that they can be ingested without affecting their demographic variables (Grant et al., 1983; Fernández et al., 2012); moreover, consumption can be voracious (Wickstrom and Castenholz, 1985). In the present study, the diet that most influenced the population parameters of Heterocypris incongruens was a toxic strain of Microcystis sp. A, decreasing survival rates and raising its net reproductive rate. Even with decreased survival rates, population growth was not lower compared to the controls. Wilson et al. (2006) conclude that in $70 \%$ of the cases studied, the microcystins had no effect on population growth and the most affected parameter was survival. This could be due to the following reasons: i) the maturity of the organisms is advanced and therefore their reproductive stage was more extensive (Roff, 2001); or ii) the survival of the organisms was not affected in the period previous to age at maturity and during reproduction, which allows a large percentage of the population reaching that stage to reproduce at least once. The data obtained in this study support the latter assumption, reporting that $50 \%$ of the organisms reached maturity, and the same percentage was obtained with Scenedesmus (control diet).

With the non-toxic strain of Microcystis sp. B, no adverse effects were observed in the derived demographic variables. This strain was collected from one of the canals of Xochimilco close to the collection site of H. incongruens which was used in this test. Studies on zooplankton suggest that populations develop tolerance to toxicity (Hairston et al., 1999; Gustafsson and Hansson, 2004; Sarnelle and Wilson, 2005; Sarnelle et al., 2010) and/or adaptations in ingesting cyanobacteria (i.e. Iyer and Rao, 1998), if they face constant exposure to these diets. The

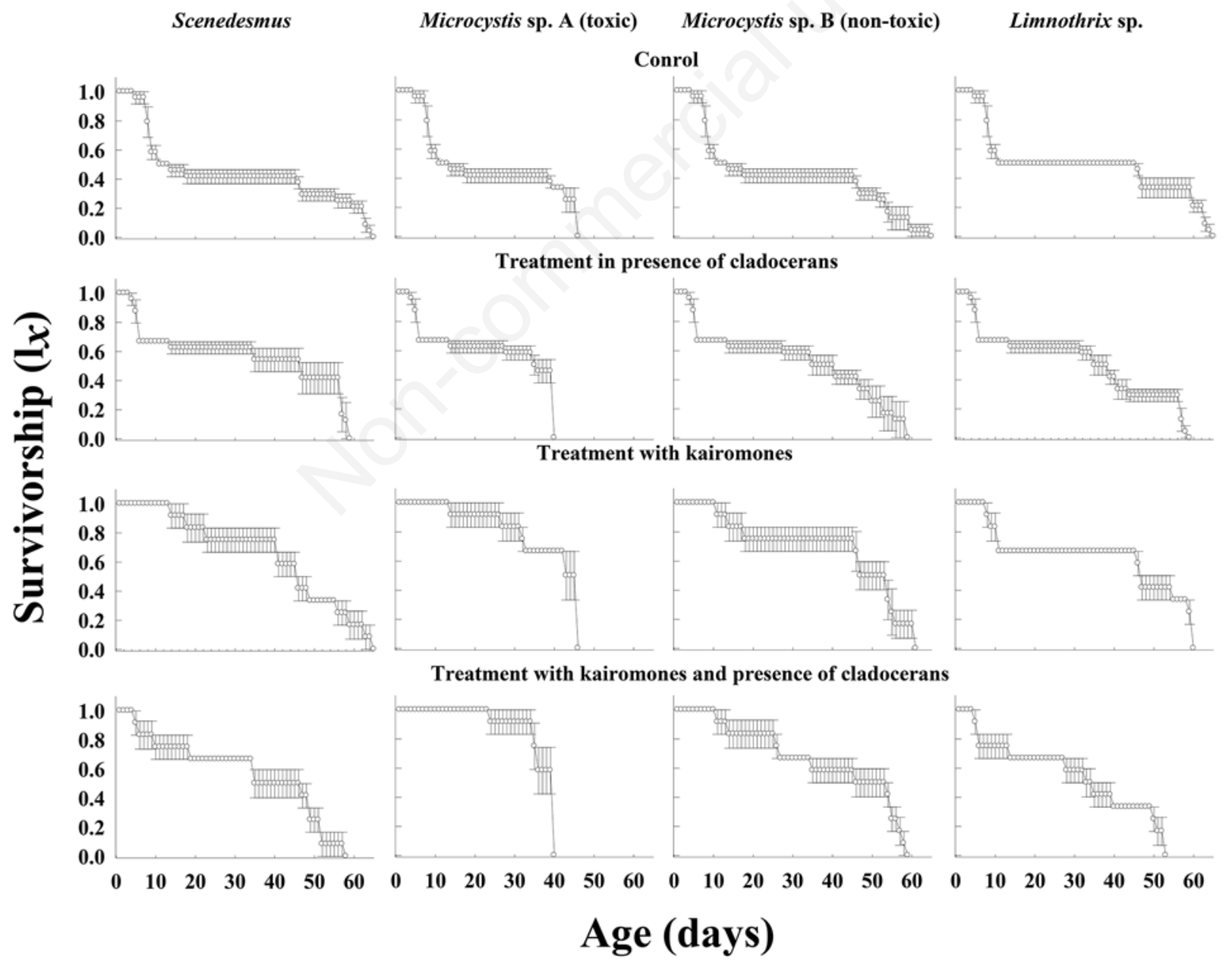

Fig. 1. Survivorship of Heterocypris incongruens fed four different diets and under four experimental conditions. Shown are mean \pm SE based on four replicate observations. 
data obtained here with $H$. incongruens and Simocephalus vetulus (Fernández et al., 2014) are congruent with the analyses of Wilson et al. (2006).

On the simultaneous consumption of cyanobacteria by the zooplankton, works undertaken have focused on the competition between species, and it is worth noting that the organisms utilized belonged to the same taxa; these studies generally conclude that one species excludes the other due to competition (Alva-Martinez et al., 2009) because they share similar characteristics in their life cycles and utilize their food resource in the same form. In this study, organisms from different taxa were used, H. incongruens (Ostracoda) and S. vetulus (Cladocera), because both species frequently co-occur in temporary water bod- ies, shallow water, ponds and fountains (Juárez-Franco et al., 2009; Fernández et al., 2012). Both organisms have similar feeding habits, but different life cycles.

The data obtained in this study show differences in the response of the demographic variables of $H$. incongruens when exposed to the cladoceran. In the presence of cladocerans, $H$. incongruens responded with a longer life expectancy and increased survival rates in the pre-reproductive stage, with an increase of $20 \%$ compared to controls. These responses have been explained as the result of a competition (Hebert, 1982; Feniova and Budaev, 2006), but S. vetulus benefitted in its population growth as did the ostracod. It has been documented that resource partitioning does help in the coexistence of species (Legeżyńska, 2008). Fernández et al.

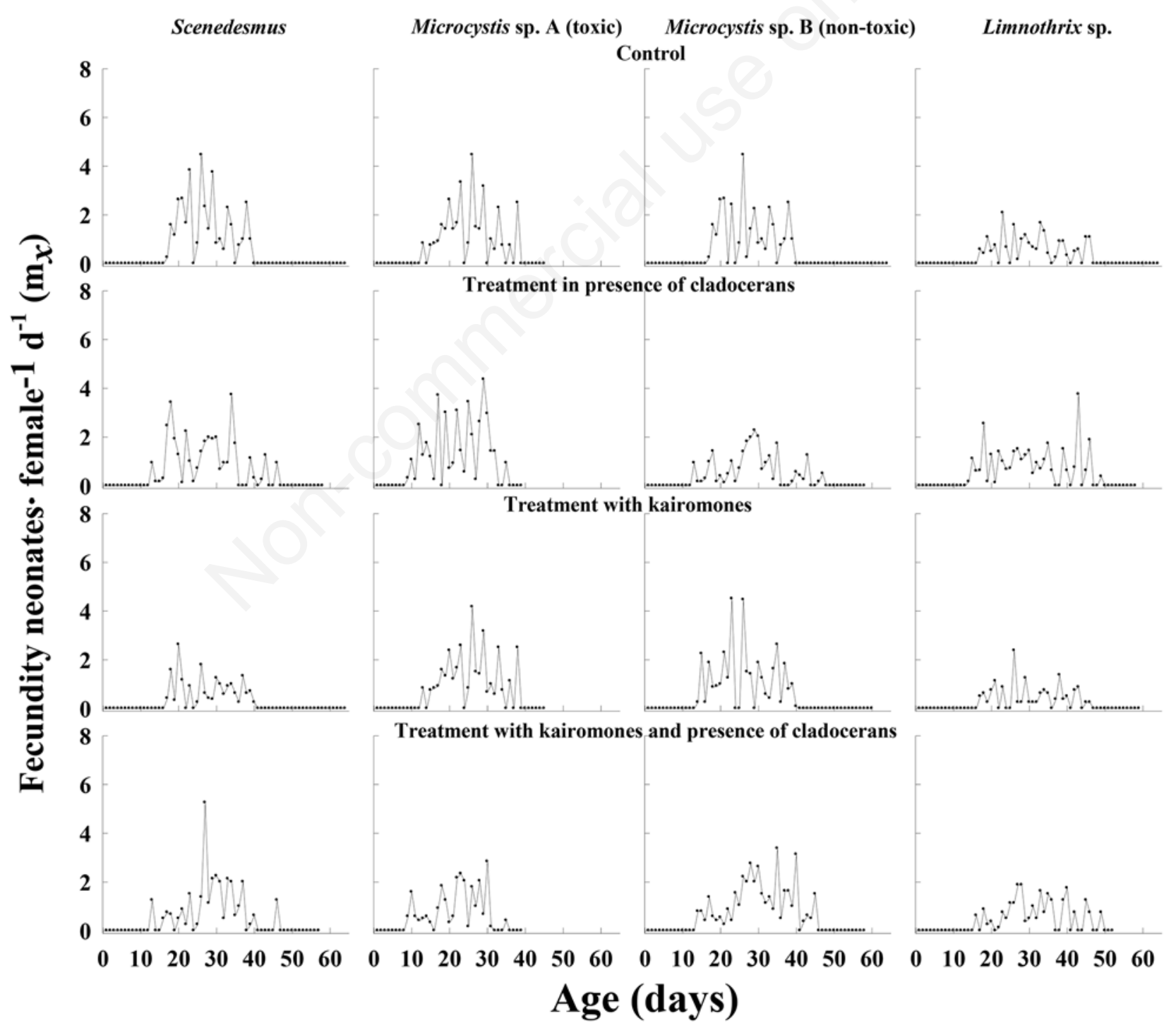

Fig. 2. Fecundity of Heterocypris incongruens fed four different diets and under four experimental conditions. Shown are mean mean \pm SE based on four replicate observations. 
Scenedesmus
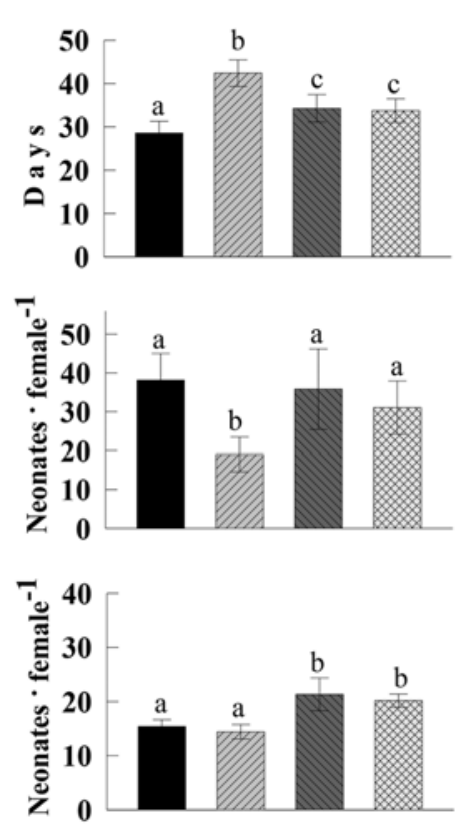

Control

Microcystis sp. A (toxic) Microcystis sp. B (non-toxic)

Limnothrix sp.

Average lifespan
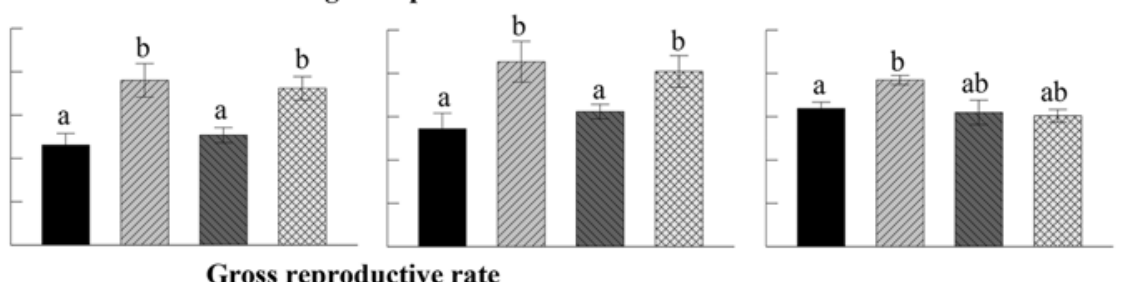

Gross reproductive rate
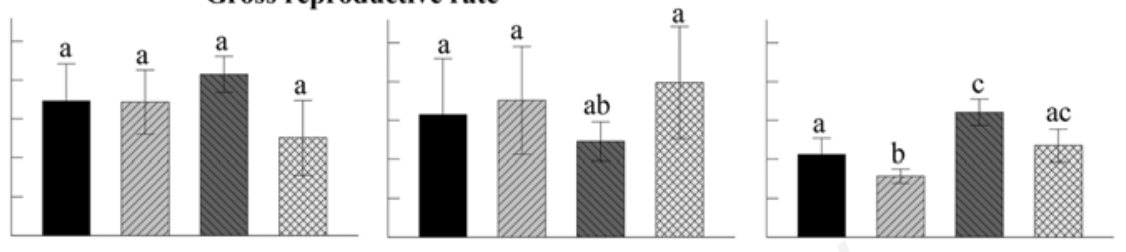

Net reproductive rate

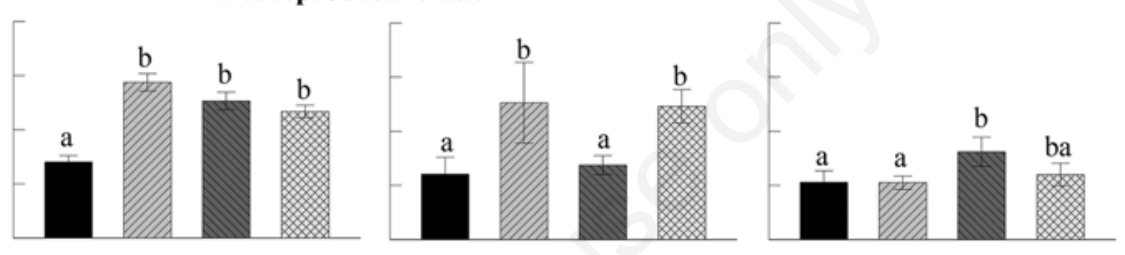

Treatments

Treatment with kairomones

Treatment with kairomones and presence of cladocerans

Fig. 3. Demographic parameters of Heterocypris incongruens fed four different diets and under four experimental conditions. Shown are mean \pm SD based on four replicate observations. Bars bearing different letters are significantly different based on the Holm-Sidak test.

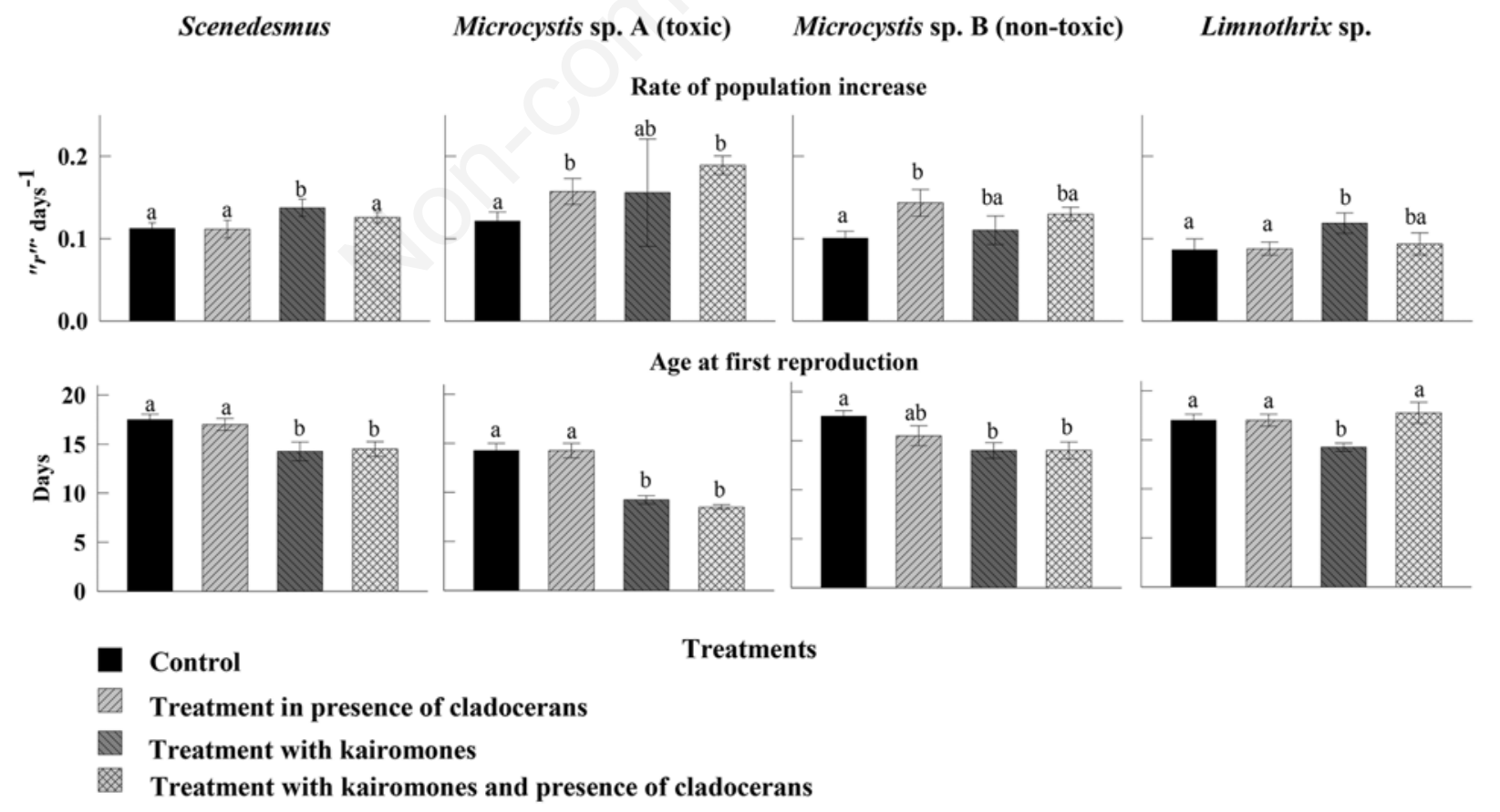

Fig. 4. Age and first reproduction and population increase of Heterocypris incongruens fed four different diets and under four experimental conditions. Shown are mean \pm SD based on four replicate observations. Bars bearing different letters are significantly different based on the Holm-Sidak test. 
(2012) observed $S$. vetulus feeding on the feces of $H$. incongruens, and although there have been no studies on the nutritional composition of the excreta, their observations suggest that the process of ingestion and digestion reduced or eliminated the toxicity of Microcystis and hence allowing the cladocerans to consume and grow on this fecal diet. This type of relationship is known as indirect facilitation (Bruno et al., 2003; Rodriguez, 2006). It should be noted that the densities of the diets used here, were similar to those in the lakes from which the test species were collected (dry weight of $23.2 \mu \mathrm{g} \cdot \mathrm{mL}^{-1}$ ), and therefore it is possible that there may be competition when food is scarce. Our previous study indicates that the ostracods did not feed on the cladocerans; the growth rate of Simocephalus vetulus, on the other hand, was higher in the presence of $H$. incongruens (Fernández et al., 2014).

Yet another factor considered in this study was the impact of vertebrate predators via chemical cues in the medium, the kairomones (Hanazato, 1995). We ensured that the fish used for obtaining kairomones consumed all provided prey ( $50 \%$ of cladocerans and ostracods $50 \%$ ) to obtain the same predation caused stress. It is common in zooplankton that a large percentage of the population dies in the early stages of its life cycle before reproducing. This pattern was observed in the controls when $50 \%$ of the population died in the first days, and this pattern becomes modified by treatment with conditioned- medium that includes fish kairomones, where data exhibits that about $80 \%$ of the population was alive during the beginning of their reproductive stage; similar trends were reported in Heterocypris reptans (McLay, 1978). Coupled with the consumption of Microcystis sp. A (toxic), the ostracods reached maturity in about ten days, which is equivalent to a one week advance with respect to previous results (Fernández et al., 2012). Orienting biological efficiency has been well documented as a response to predation by zooplankton (Hanazato et al., 2001; Roff, 2001). The anticipated benefit due to reproductive maturity was observed in the treatment of Microcystis sp. A (toxic) + fish kairomones, which yielded a population growth of 0.20 individuals day ${ }^{-1}$; this growth rate was the highest obtained for this organism in this study. It has been observed that organisms under stress mature and reproduce faster (Hanazato et al., 2001) and in this treatment the ostracods faced three different stress factors, toxic food, indirect presence of predators and the presence of competitors.

\section{CONCLUSIONS}

Species of the genus Heterocypris have been recorded in different places with very different environmental conditions (Mezquita et al., 1999; Petkowski et al., 2000; Rossi et al., 2013), and H. incongruens can be considered as cosmopolitan or a widely distributed species (Mezquita et al., 1999). They are able to sustain dense populations in places with several stressors acting upon them simul- taneously, as in eutrophic or temporary water bodies. Our study highlights their ability to withstand multiple stressors. Considering their ability to consume cyanobacteria, they can perhaps be used effectively for controlling cyanobacteria in eutrophic environments worldwide.

\section{ACKNOWLEDGMENTS}

RF thanks Programa de Doctorado en Ciencias Biológicas y de la Salud, Autonomous Metropolitan University, Campus Xochimilco (UAM X) and CONACyT for a doctoral scholarship (236535) and SNI assistance (68670). The authors are grateful to UNAM (PAPIIT 216315) for financial assistance.

\section{REFERENCES}

Alekseev VR, De Stasio BT, Gilbert JJ, 2007. Diapause in aquatic invertebrates, theory and human use. Springer, Dordrecht: $260 \mathrm{pp}$.

Aguilar-Alberola JA, Mesquita-Joanes F, 2011. Population dynamics and tolerance to desiccation in a crustacean ostracod adapted to life in small ephemeral water bodies. Limnologica 41:348-355.

Alva-Martínez AF, Sarma SSS, Nandini S, 2007. Effect of mixed diets (cyanobacteria and green algae) on the population growth of the cladocerans Ceriodaphnia dubia and Moina macrocopa. Aquat. Ecol. 41:579-585.

Alva-Martínez AF, Fernández R, Sarma SSS, Nandini S, 2009. Effect of mixed toxic diets (Microcystis and Chlorella) on the rotifers Brachionus calyciflorus and Brachionus havanaensis cultured alone and together. Limnologica 39:302-305.

Begon M, Townsend CR, Harper JL, 2006. Ecology: from individuals to ecosystems. Blackwell Publishing, Oxford: 752 pp.

Bruno JF, Kennedy CW, 2007. Patch-size dependent habitat modification and facilitation on New England cobble beaches by Spartina alterniflora. Oecologia 122:98-108.

Bruno JF, Stachowicz JJ, Bertness MD, 2003. Inclusion of facilitation into ecological theory. Trends Ecol. Evol. 18:119-125.

Carbonel P, Colin JP, Danielopol DL, Löffler H, Neustreva I, 1988. Paleoecology of limnic ostracodes: a review of some major topics. Palaeogeogr. Palaeocli 62:413-461.

Clesceri L, Greenberg A, Eaton AD, 1998. Standard methods for the examination of water and wastewater, 20th ed. American Public Health Association.

Delorme LD, 1991. Ostracoda, p. 691-722. In: H. Thorp and A.P. Covich (eds.), Ecology and classification of North American freshwater invertebrates. Academic Press.

Diner MP, Odum EP, Hendrix PF, 1986. Comparison of the roles of ostracods and cladocerans in regulating community structure and metabolism in freshwater microcosms. Hydrobiologia 133:59-63.

Dodson SI, Lillie RA, Will-Wolf S, 2005. Land use, water chemistry, aquatic vegetation, and zooplankton community structure of shallow lakes. Ecol. Appl. 15:1191-1198.

Feniova IY, Budaev SV, 2006. Estimation of the possibility of cladoceran invasion and survival under conditions of competition in mesotrophic Lake Glubokoe. Russian J. Ecol. 37:200-204.

Fernández R, Nandini S, Sarma SSS, 2012. A comparative study 
on the ability of tropical micro-crustaceans to feed and grow on cyanobacterial diets. J. Plankton Res. 34:719-731.

Fernández R, Nandini S, Sarma SSS, Castellanos-Paez ME, 2014. Effects of cyanobacteria, fish kairomones, and the presence of ostracods on the demography of Simocephalus vetulus (Cladocera). Invertebr. Biol. 133:371-380.

Gliwicz ZM, 1990. Why do cladocerans fail to control algal blooms? Hydrobiologia 200:83-97.

Gliwicz ZM, 2003. Cladoceran densities, day-to-day variability in food selection by smelt, and the birth-rate-compensation hypothesis. Hydrobiologia 526:171-186.

Grant IF, Egan EA, Alexander M, 1983. Measurement of rates of grazing of the ostracod Cyprinotus carolinensis on bluegreen algae. Hydrobiologia 106:199-208.

Gross N, Liancourt P, Choler P, Suding KN, Lavorel S, 2010. Strain and vegetation effects on local limiting resources explain the outcomes of biotic interactions. Perspect. Plant Ecol., Evol. Syst. 12:9-19.

Gulati RD, 1990. Structural and grazing responses of zooplankton community to biomanipulation of some Dutch water bodies. Hydrobiologia 200:99-118.

Gustafsson S, Hansson LA, 2004. Development of tolerance against toxic cyanobacteria in Daphnia. Aquatic Ecol. 38:37-44.

Hairston NG, Perry LJ, Bohonak AJ, Fellows MQ, Kearns CM, Engstrom DR, 1999. Population biology of a failed invasion: paleolimnology of Daphnia exilis in upstate New York. Limnol. Oceanogr. 44:477-486.

Hanazato T, 1995. Toxic cyanobacteria and the zooplankton community, p. 79-102. In: M.F. Watanabe, K. Harada, W.W. Carmicheal and H. Fujiki (eds.), Toxic microcystis. CRC Press.

Hanazato T, Fueki K, Yoshimoto M, 2001. Fish-induced lifehistory shifts in the cladocerans Daphnia and Simocephalus: are they positive or negative responses? J. Plankton Res. 23:945-951.

Harper D, 1992. The ecological relationships of aquatic plants at Lake Naivasha, Kenya. Hydrobiologia 232:65-71.

Hebert PD, 1982. Competition in zooplankton communities. Ann. Zool. Fenn. 19:349-356.

Horne FR, 1993. Survival strategy to escape desiccation in a freshwater ostracod. Crustaceana 65:53-61.

Iyer N, Rao TR, 1998. Somatic and population growth in selected cladoceran and rotifer species offered the cyanobacterium $\mathrm{Mi}$ crocystis aeruginosa as food. Aquat. Ecol. 31:283-298.

Juárez-Franco MF, Sarma SSS, Nandini S, 2009. Population dynamics of Heterocypris incongruens (Ramdohr, 1808) (Ostracoda, Cyprididae) in relation to diet type (algae and organic waste) and amount of food. Crustaceana 82:743-752.

Krebs CJ, 2009. Ecology: the experimental analysis of distribution and abundance. Benjamin Cummings, San Francisco: 655 pp.

Külköylüoğlu O, Dügel M, Kılıç M, 2007. Ecological requirements of Ostracoda (Crustacea) in a heavily polluted shallow lake, Lake Yeniçağa (Bolu, Turkey). Hydrobiologia 585:119-133.

Lahr J, 1997. Ecotoxicology of organisms adapted to life in temporary freshwater ponds in arid and semi-arid regions. Arch. Environ. Con. Tox. 32:50-57.

Lampert W, 1986. Response of the respiratory rate of Daphnia magna to changing food conditions. Oecologia 70:495-501.

Lampert W, 1987. Laboratory studies on zooplankton-cyanobacteria interactions. New Zeal. J. Mar. Fresh. 21:483-490.
Legeżyńska J, 2008. Food resource partitioning among Arctic sublittoral lysianassoid amphipods in summer. Polar Biol. 31:663-670.

Mayeli SM, Nandini S, Sarma SSS, 2004. The efficacy of Scenedesmus morphology as a defense mechanism against grazing by selected species of rotifers and cladocerans. Aquat. Ecol. 38:515-524.

McLay CL, 1978. Comparative observations on the ecology of four species of ostracods living in a temporary freshwater puddle. Can. J. Zool. 56:663-675.

Mezquita F, Hernández R, Rueda J, 1999. Ecology and distribution of ostracods in a polluted Mediterranean river. Palaeogeogr. Palaeocl. 148:87-103.

Moss B, Madgwick J, Phillips G, 1996. A guide to restoration of nutrient-enriched shallow lakes. Environment Agency \& Broads Authority, East Anglia: 214 pp.

Pérez-Morales A, Sarma SSS, Nandini S, 2014. Feeding and filtration rates of zooplankton (rotifers and cladocerans) fed toxic cyanobacterium (Microcystis aeruginosa). J. Environ. Biol. 35:1013-1020.

Petkowski T, Scharf B, Keyser D, 2000. New and little known ostracods of the genus Heterocypris (Crustacea, Ostracoda) from the Balkan Peninsula. Limnologica 30:45-57.

Rapport DJ, 1983. The stress-response environmental statistical system and its applicability to the Laurentian Lower Great Lakes. Stat. J. U.N. Econ. Comm. Eur. 1:377-405.

Rodriguez LF, 2006. Can invasive species facilitate native species? Evidence of how, when, and why these impacts occur. Biol. Invasions 8:927-939.

Roff DA, 2001. Age and size at maturity, p. 99-112. In:, Concepts and case studies. Oxford University Press.

Rossi V, Martorella A, Menozzi P, 2013. Hatching phenology and voltinism of Heterocypris barbara (Crustacea: Ostracoda) from Lampedusa (Sicily, Italy). J. Limnol. 72:e18.

Sarnelle O, Wilson AE, 2005. Local adaptation of Daphnia pulicaria to toxic cyanobacteria. Limnol. Oceanogr. 50:1565-1570.

Sarnelle O, Gustafsson S, Hansson LA, 2010. Effects of cyanobacteria on fitness components of the herbivore Daphnia. J. Plankton Res. 32:471-477.

Stabell OB, Ogbebo F, Primicerio R, 2003. Inducible defences in Daphnia depend on latent alarm signals from conspecific prey activated in predators. Chem. Senses 28:141-153.

Tillmanns AR, Wilson AE, Pick FR, Sarnelle O, 2008. Metaanalysis of cyanobacterial effects on zooplankton population growth rate: species-specific responses. Fund. Appl. Limnol. 171:285-295.

Vandekerkhove J, Martens K, Rossetti G, Mesquita-Joanes F, Namiotko T, 2013. Extreme tolerance to environmental stress of sexual and parthenogenetic resting eggs of Eucypris virens (Crustacea, Ostracoda). Freshwater Biol. 58:237-247.

Wickstrom CE, Castenholz RW, 1985. Dynamics of cyanobacterial and ostracod interactions in an Oregon hot spring. Ecology 66:1024-1041.

Williams M, Siveter DJ, Salas MJ, Vannier J, Popov LE, Pour MG, 2008. The earliest ostracods: the geological evidence. Senckenbergiana lethaea 88:11-21.

Wilson AE, Sarnelle O, Tillmanns AR, 2006. Effects of cyanobacterial toxicity and morphology on the population growth of freshwater zooplankton: meta-analyses of laboratory experiments. Limnol. Oceanogr. 51:1915-1924. 